\title{
Outcomes with multi-disciplinary management of central lung tumors with CT-guided percutaneous high dose rate brachyablation
}

Stephanie M. Yoon ${ }^{1}$, Robert Suh², Fereidoun Abtin², Drew Moghanaki ${ }^{1,3}$, Scott Genshaft ${ }^{2}$, Mitchell Kamrava ${ }^{4}$, Alexandra Drakaki ${ }^{5}$, Sandy Liu ${ }^{5}$, Puja Venkat ${ }^{1}$, Alan Lee ${ }^{1}$ and Albert J. Chang ${ }^{1 *}$ (D)

\begin{abstract}
Background: Centrally located lung tumors present treatment challenges given their proximity to mediastinal structures including the central airway, esophagus, major vessels, and heart. Therapeutic options can be limited for medically inoperable patients, particularly if they have received previous thoracic radiotherapy. High dose rate (HDR) brachyablation was developed to improve the therapeutic ratio for patients with central lung tumors. The purpose of this study is to report initial safety and efficacy outcomes with this treatment for central lung malignancies.
\end{abstract}

Methods: From September 2015 to August 2019, a total of 25 patients with 37 pulmonary tumors were treated with percutaneous HDR brachyablation. Treatment was delivered by a multi-disciplinary team of interventional radiologists, pulmonologists, and radiation oncologists. Twenty-three patients received a median dose of 21.5 Gy (range 15-27.5) in a single fraction, whereas two patients received median dose of $24.75 \mathrm{~Gy}$ (range 24-25.5) over 2-3 fractions. Tumor local control (LC) was evaluated by Response Evaluation Criteria in Solid Tumors v1.1. Treatment-related toxicities were graded by Common Terminology Criteria for Adverse Events v5.0, with adverse events less than 90 days defined as acute, and those occurring later were defined as late. LC, progression-free survival (PFS), and overall survival (OS) rates were estimated by the Kaplan-Meier method.

Results: Of 37 treated tumors, $88 \%$ were metastatic. Tumor location was central and ultra-central in $24.3 \%$ and $54.1 \%$, respectively. Average tumor volume was $11.6 \mathrm{~cm}^{3}$ (SD 12.4, range 0.57-62.8). Median follow-up was 19 months (range 3-48). Two-year LC, PFS, and OS were 96.2\%, 29.7\%, and 65.5\%, respectively. Thirteen of 39 (33.3\%) catheter implantation procedures were associated with trace minor pneumothorax requiring no intervention, 1 (2.5\%) procedure with minor radiographic pulmonary hemorrhage, and 4 (10.3\%) with major pneumothorax requiring chest tube insertions. All procedural complications resolved within $24 \mathrm{~h}$ from treatment. Acute grade 1-2 toxicity was identified in 4 patients, whereas none developed late toxicity beyond 90 days of follow-up.

Conclusion: Percutaneous HDR brachyablation is a safe and promising treatment option for centrally located primary and metastatic lung tumors. Future comparisons with stereotactic body radiotherapy and other ablative techniques are warranted to expand multi-disciplinary management options.

*Correspondence: AJChang@mednet.ucla.edu

1 Department of Radiation Oncology, University of California Los Angeles, 200 Medical Plaza Driveway, Suite B265, Los Angeles, CA 90095, USA

Full list of author information is available at the end of the article permits use, sharing, adaptation, distribution and reproduction in any medium or format, as long as you give appropriate credit to the original author(s) and the source, provide a link to the Creative Commons licence, and indicate if changes were made. The images or other third party material in this article are included in the article's Creative Commons licence, unless indicated otherwise in a credit line to the material. If material is not included in the article's Creative Commons licence and your intended use is not permitted by statutory regulation or exceeds the permitted use, you will need to obtain permission directly from the copyright holder. To view a copy of this licence, visit http://creativecommons.org/licenses/by/4.0/. The Creative Commons Public Domain Dedication waiver (http://creativeco mmons.org/publicdomain/zero/1.0/) applies to the data made available in this article, unless otherwise stated in a credit line to the data. 
Keywords: Brachytherapy, Interstitial brachytherapy, High-dose-rate brachytherapy, Brachyablation, Pulmonary metastasis

\section{Introduction}

The uncontrolled growth of central tumors can contribute to significant morbidity, including hemoptysis, lung collapse, vascular obstruction, and dysphagia. Yet, treatments can be challenging given their close proximity to critical mediastinal structures including the central airway, esophagus, major vessels, and heart. Patients who are deemed poor candidates for surgery are often recommended external beam radiotherapy. Whenever longterm control is desired, short courses of stereotactic body radiotherapy (SBRT) can achieve local control (LC) rates of $80-90 \%[1,2]$. However, SBRT to centrally located tumors has been associated with severe toxicities [2-6], which has led to the development of alternative strategies such as image-guided thermal ablation (IGTA) that has been associated with variable levels of LC and complications related to applicator placement and delivery of thermal energy [7-9].

Despite such challenges, local control of centrally located tumors is critical for palliation and to improve quality of life. Moreover, treatment of patients with limited metastases for curative intent is increasing [10-12]. This oligometastatic paradigm involves strategic combinations of locoregional therapies and effective systemic agents.

To develop a potentially safer and more effective treatment strategy for central lung tumors, our institution introduced percutaneous high dose rate (HDR) brachyablation for lung tumors in 2015The term "brachyablation" is commonly referenced at our institution to facilitate communication with our multi-disciplinary colleagues who are familiar with radiofrequency ablation, microwave ablation, and cryoablation. To our knowledge, our institution was the first to offer percutaneous brachyablation in the United States for pulmonary tumors. This initial study reports the safety and efficacy of this treatment in the initial 25 patients treated with this technique.

\section{Materials and methods}

A retrospective cohort study of the first 25 consecutive patients with pulmonary tumors treated with CT-guided interstitial HDR brachytherapy from September 2015 to August 2019 was conducted at a single institution after institutional review board approval. Central tumors were lesions located within $2 \mathrm{~cm}$ from the proximal bronchial tree or mediastinum; tumors whose CTV abutted the aforementioned structures were considered ultracentral. Patients had been considered for treatment in a multi-disciplinary setting if they had biopsy proven primary non-small cell lung cancer (NSCLC), locally recurrent NSCLC, or metastatic pulmonary tumors confirmed with growth on imaging, who were medically inoperable, not surgical candidates, or refused surgery.

\section{Interstitial catheter implantation}

Catheter placements were performed in collaboration with the Department of Radiology Thoracic Interventional Services. With exception of one patient, all patients were treated on an outpatient basis. At the onset of their procedure, patients underwent a non-contrast $\mathrm{CT}$ for tumor localization, and a mark was placed on the overlying skin. Local anesthesia with lidocaine $(2 \%)$ was administered to the skin surrounding the marked site, and bupivacaine $(0.5 \%)$ provided deeper soft tissue and pleural anesthesia. Patients received conscious sedation according to individual needs. A single 17-gauge co-axial needle (Argon Medical Devices, Athens, TX, USA) was inserted percutaneously through the marked location using image guidance with serial CT scans to confirm accurate needle trajectory as the needle tip advanced to the distal or deep margin of the targeted tumor (Fig. 1A). A single 4F brachytherapy catheter (Best Medical International Inc., Springfield, VA, USA) was introduced through the co-axial needle until both tips were coincident with each other intratumorally. Additional needles and catheters were introduced as needed to ensure adequate dosimetry of the tumor, especially when tumor diameter exceeded $3 \mathrm{~cm}$ and/or when tumor shape was non-spherical.

\section{Brachytherapy planning and treatment delivery}

A planning CT simulation scan using $2 \mathrm{~mm}$ slice thickness was obtained. Images were transferred to the brachytherapy treatment planning system (TPS) (Oncentra Brachytherapy, version 4.5.2, Elekta Inc., Veenendaal, Netherlands). Catheters were digitized and reconstructed on the TPS. The clinical target volume (CTV) was delineated on the simulation scan, which included the gross tumor and suspicious areas from prior diagnostic scans. Critical organs-at-risk (OAR) were contoured on each slice. Inverse-planning was utilized, and a prescription range of 15 to $27.5 \mathrm{~Gy}$ was delivered to the CTV periphery in a single treatment fraction corresponding to a biologic effective dose $\left(\mathrm{BED}_{3}\right) \geq 100$ Gy (Fig. 1B-D). Two patients (8\%) were treated with multiple fractions to deliver a median dose of 24.8 Gy (range 24.0-25.5); one patient 


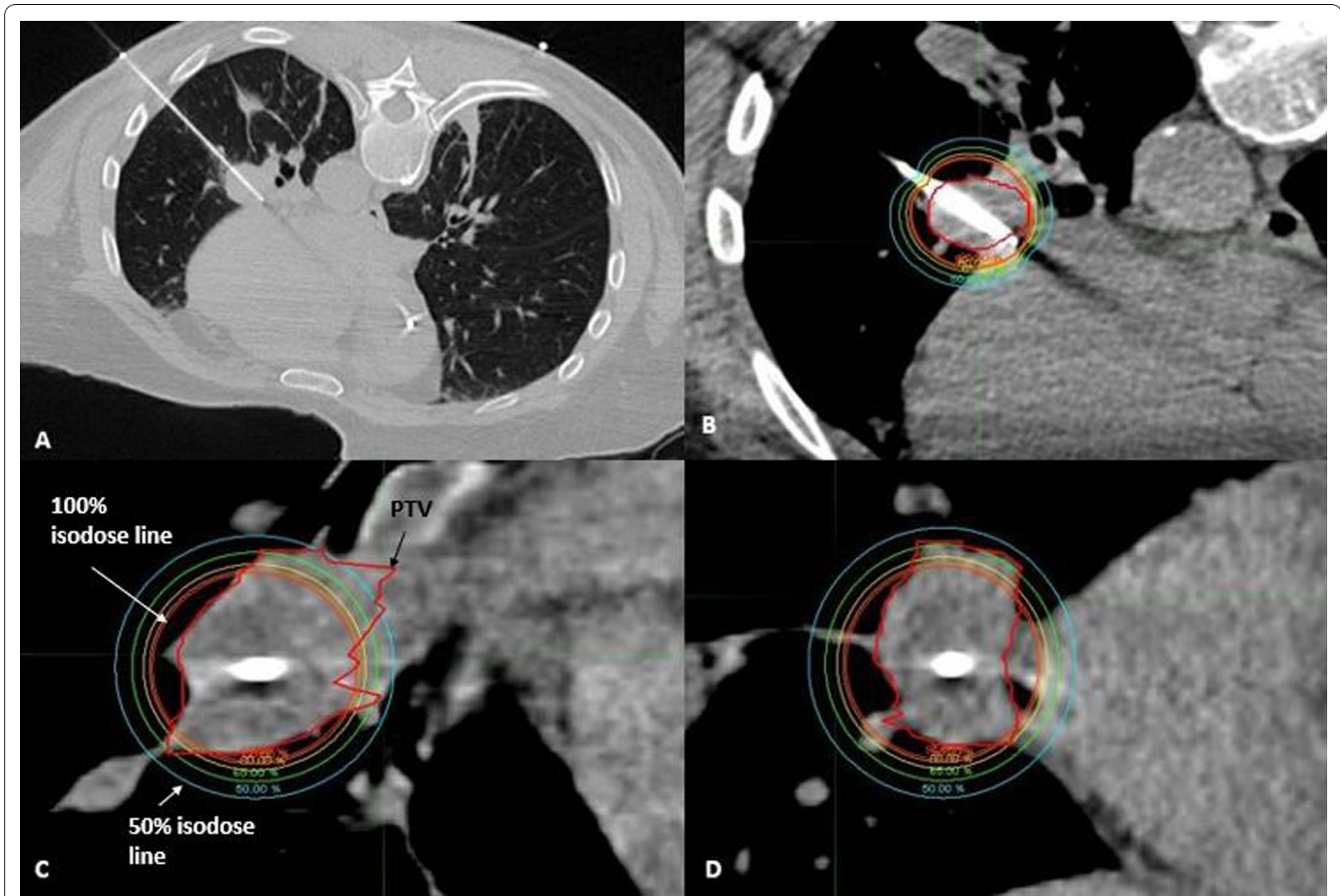

Fig. 1 A 60-year old man with metastatic leiomyosarcoma presenting with multiple lung metastasis. He had undergone multiple microwave ablations for other lung tumors. A malignant left sub-hilar lymph node continued to grow despite treatment with multiple cycles of doxorubicin and olaratumab. This tumor was treated with CT-guided interstitial HDR brachyablation. A Placement of co-axial needle under CT-guidance during brachytherapy catheter implantation. A co-axial needle was advanced percutaneously and placed directly into the ultra-central tumor abutting the heart. B Axial C Sagittal and D Coronal views of resultant treatment isodose distribution

underwent 2 separate outpatient catheter implantations for each fraction, and another had one catheter implantation and hospitalized overnight to receive 3 treatment fractions in 4-6-h intervals. Dose fractionation schemas were compared on common numeric scores using $\mathrm{BED}_{3}$ and equivalent dose in 2 Gy per fraction (EQD2) (Additional file 1: Appendix). A minimum of $95 \%$ of the CTV was to receive the prescription dose $(\mathrm{V} 100 \%>95 \%)$ and the dose that $90 \%$ of the CTV received (D90\%) was optimized. OAR dose tolerance limits were prioritized as outlined by AAPM Task Group 101 [13]. Maximum dose, corresponding to the most irradiated $2 \mathrm{cc}$ of the heart, esophagus, trachea, proximal bronchial tree, and chest wall (D2cc) as well as ipsilateral lung V5Gy, V20Gy, and mean dose were recorded. Iridium-192 was delivered with an HDR remote afterloader (Nucletron B.V., Model 136149A02 Flexitron HDR remote afterloader, Elekta Inc., Veenendaal, Netherlands). After treatment, both the catheter(s) and co-axial needle were removed with placement of a resorbable hydrogel (BioSentry Tract Sealant
System, Surgical Specialties Corp., Tijuana, MX) to seal the pleural site of entry. A final CT scan was acquired after catheter removal.

\section{Follow-up and statistical analysis}

Patients were routinely followed within 7 days of treatment and at least every 3 months with surveillance chest CT scans. Target lesions were assessed by the Response Evaluation Criteria in Solid Tumors (RECIST) by two independent radiation oncologists and a thoracic radiologist [14], and scored as stable disease, partial response, or complete response. Growth of the treated tumor compared to previous CT scans was considered as local failure. Toxicities were graded by Common Terminology Criteria for Adverse Events (CTCAE) version 5.0; toxicities less than or equal to 90 days after treatment were defined as acute, and those occurring afterwards were defined as late.

Descriptive statistics were reported for patient demographics, clinical features, procedural complications, 
and toxicity. Fisher's exact test assessed the association between LC and several covariates: implantation setting (non-metastatic vs. metastatic), prior IGTA, lung radiation, systemic therapies, tumor location, and total dose ( $<20$ Gy vs. $\geq 20$ Gy). Time-to-event analysis was performed with the endpoint defined as time from the start of first percutaneous HDR brachyablation procedure. Endpoints were time to local failure, disease progression (local, regional, or distant), and death. Tumor LC, progression free survival (PFS) and overall survival (OS) rates, respectively, were estimated using the KaplanMeier method. All analyses were conducted using Stata IC version 15 (StataCorp, College Station, Texas, USA). This study followed the Strengthening the Reporting of Observational Studies in Epidemiology (STROBE) reporting guidelines.

\section{Results}

Twenty-five patients with 37 tumors were treated with a total of 39 CT-guided percutaneous HDR brachyablation procedures between September 2015 to August 2019. Baseline patient characteristics are summarized in Table 1 . Twenty-two $(88.0 \%)$ patients had metastatic lung tumors, $2(8.0 \%)$ had primary NSCLC, and 1 (4.0\%) had locally recurrent NSCLC. The most common histologies were renal cell carcinoma $(n=6,24 \%)$, NSCLC $(n=5,20 \%)$, and soft tissue sarcoma $(n=5,20 \%)$. Among patients with pulmonary metastasis, 8 (36.3\%) had extrathoracic disease. With the exception of one, all tumors had not received any prior local treatment. Twenty-three (92.0\%) patients received at least one prior systemic therapy or local treatment for tumors in other areas of the lung: systemic therapy $(72.0 \%)$, radiotherapy $(56.0 \%)$, or IGTA (32.0\%).

Of 37 treated tumors, 20 (54.1\%) were ultra-central and 9 (24.3\%) were central, respectively. The average CTV was $11.6 \mathrm{~cm}^{3}$ (SD 12.4, range 0.57-62.8). Mean CTV V125\% and V150\% were 81.2\% (SD 11.4) and 70.7\% (SD 13.1), respectively. The mean lung dose to the ipsilateral lung was 2.17 Gy (SD 1.53). Mean V5Gy and V20Gy to the ipsilateral lung were $7.84 \%$ (SD 8.32) and $0.85 \%$ (1.06). Maximum dose to the most irradiated $2 \mathrm{cc}$ to the heart, esophagus, trachea/proximal bronchus, and chest wall were 4.58 Gy (SD 4.95), 1.02 Gy (SD 1.86), 2.85 Gy (SD 3.61), and 1.98.Gy (SD 4.13), respectively.

Median follow-up time was 19 months (range 3-48). Twenty-one patients representing 33 tumors were evaluable for response assessment. Six (18.2\%) of 33 tumors exhibited complete local response, 15 (45.5\%) partial response, and 11 (33.3\%) stable disease. One tumor (3.0\%) demonstrated local progression. The HDR prescription dose to this tumor had been decreased to minimize the risk of injuring to the central airway and
Table 1 Baseline patient characteristics

\begin{tabular}{|c|c|}
\hline Age, mean (SD) & $66(11.6)$ \\
\hline \multicolumn{2}{|l|}{ Gender, n (\%) } \\
\hline Female & $9(36 \%)$ \\
\hline Male & $16(64 \%)$ \\
\hline \multicolumn{2}{|l|}{ ECOG performance status, $\mathrm{n}(\%)$} \\
\hline 0 & $10(40 \%)$ \\
\hline 1 & $15(60 \%)$ \\
\hline $2+$ & $0(0 \%)$ \\
\hline \multicolumn{2}{|l|}{ Lesion type, n (\%) } \\
\hline Primary NSCLC & $2(8 \%)$ \\
\hline Locally recurrent & $1(4 \%)$ \\
\hline Metastasis & $22(88 \%)$ \\
\hline \multicolumn{2}{|l|}{ Histology, n (\%) } \\
\hline Renal cell carcinoma & $6(24 \%)$ \\
\hline NSCLC & $5(20 \%)$ \\
\hline Soft tissue sarcoma & $5(20 \%)$ \\
\hline Gynecological & $2(8 \%)$ \\
\hline Hepatocellular carcinoma & $2(8 \%)$ \\
\hline Other ${ }^{\mathrm{a}}$ & $5(20 \%)$ \\
\hline CTV volume (cc), mean (SD) & $11.6(12.4)$ \\
\hline \multicolumn{2}{|l|}{ Lesion location ${ }^{\mathrm{b}}, \mathrm{n}(\%)$} \\
\hline Ultra-central & $20(54.1 \%)$ \\
\hline Parenchymal target & $13(65 \%)$ \\
\hline Hilar/nodal target & $7(35 \%)$ \\
\hline Central & $9(24.3 \%)$ \\
\hline Peripheral & $8(21.6 \%)$ \\
\hline \multicolumn{2}{|l|}{ Prior therapy for different lung tumors, n (\%) } \\
\hline Systemic therapy & $18(72 \%)$ \\
\hline Lung radiation (EBRT or brachytherapy) & $14(56 \%)$ \\
\hline Minimally invasive procedure & $8(32 \%)$ \\
\hline None & $2(8 \%)$ \\
\hline
\end{tabular}

SD, standard deviation; ECOG, Eastern Cooperative Oncology Group; NSCLC, non-small cell lung cancer; CTV, clinical target volume; EBRT, external beam radiotherapy

aOther histology included colorectal cancer, salivary gland tumors, thyroid cancer, carcinoid tumor

${ }^{\mathrm{b}}$ Per-lesion basis $(\mathrm{n}=37)$, all other results are reported on per-patient basis $(n=25)$

mediastinal structures due to prior exposure to external beam radiation. Two- and 3- year LC were 96.2\% (Fig. 2). No clinical or treatment covariates were associated with LC. Thirteen (52.0\%) patients developed systemic disease progression after treatment, 8 in other areas of the lung and 5 outside. The $2-$ and 3 -year PFS and OS rates were $29.7 \%$ and $65.5 \%$, respectively (Fig. 3A, B).

Table 2 summarizes procedural complications and treatment-related toxicities. Thirteen of 39 (33.3\%) procedures were associated with minor pneumothoraces requiring no intervention, 1 (2.5\%) led to a minor radiographic pulmonary hemorrhage requiring no 

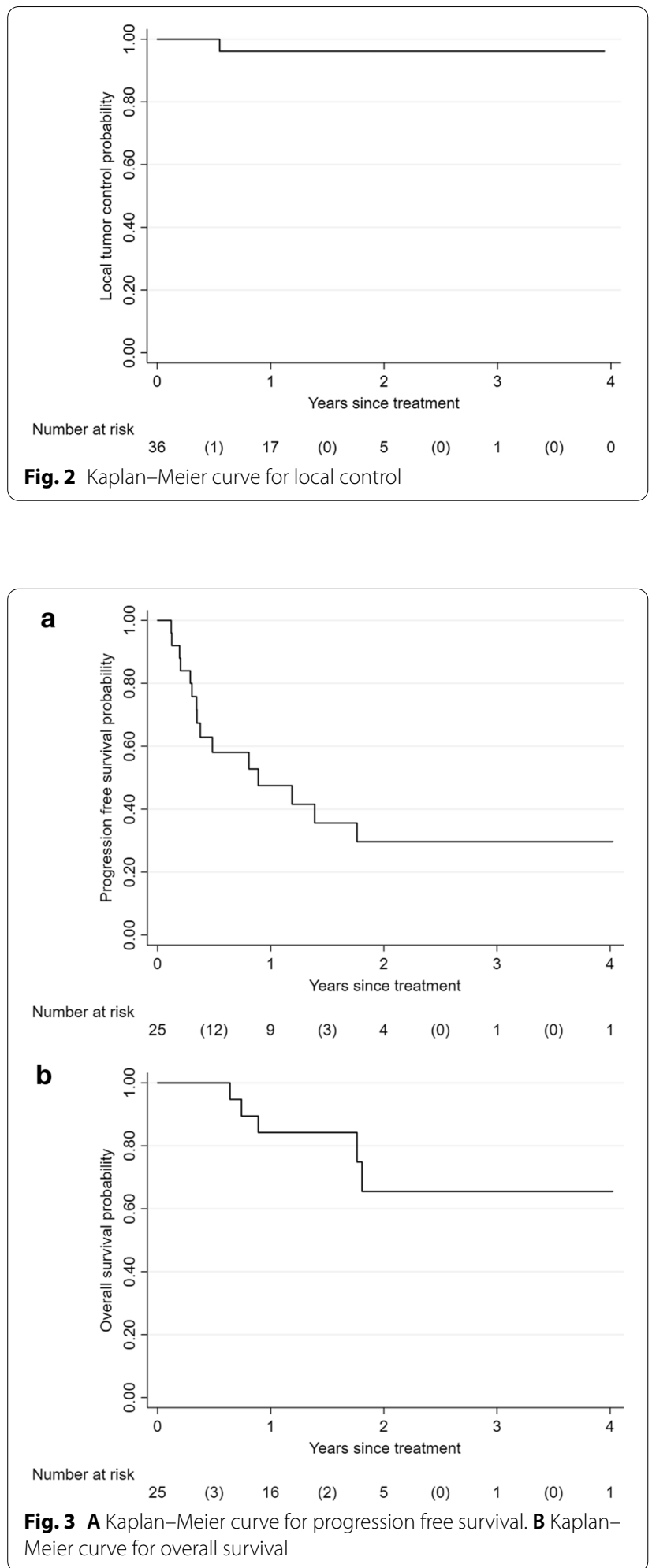

intervention, and 4 (10.3\%) were associated with a major pneumothorax requiring chest tube insertions. All procedural complications resolved within $24 \mathrm{~h}$ from treatment.
Table 2 Rates of procedural complications and treatmentrelated toxicities following CT-guided HDR interstitial brachytherapy ablation

\begin{tabular}{ll}
\hline Procedural complication rate $^{\mathbf{a}}$ & Total procedures $(\mathbf{n}=\mathbf{3 9})$ \\
\hline Minor pneumothorax & $13(33.3 \%)$ \\
Major pneumothorax & $4(10.3 \%)$ \\
Pulmonary hemorrhage $^{b}$ & $1(2.5 \%)$ \\
Acute toxic events & Total evaluable patients $(\mathrm{n}=22)$ \\
Grade 0 & $18(81.8 \%)$ \\
Grade 1 & $2(9.1 \%)$ \\
Grade 2 & $2(9.1 \%)$ \\
Grade $\geq 3$ & $0(0 \%)$ \\
Late toxic events & Total evaluable patients $(\mathrm{n}=18)$ \\
Grade 0 & $18(100 \%)$ \\
Grade 1 & $0(0 \%)$ \\
Grade 2 & $0(0 \%)$ \\
Grade $\geq 3$ & $0(0 \%)$
\end{tabular}

${ }^{a}$ All procedural complication rates self-resolved within $24 \mathrm{~h}$

${ }^{\mathrm{b}}$ Pulmonary hemorrhage was grade 1

Twenty-two patients representing 32 lesions had data available for acute toxicity evaluations. Eighteen (81.8\%) patients did not experience acute toxicities. Two patients developed grade 1 acute toxicities (cough and pain), and 2 patients experienced grade 2 toxicity (pneumonitis and pain). Post-treatment toxicities were limited to (ultra) central tumors, and resolved within 1-2 weeks. Eighteen patients with 30 lesions had available late toxicity data, none of whom developed late treatment-related toxicities. One patient experienced mild dyspnea on exertion 5 months after treatment, which was attributed to prior smoking and multiple surgical lung resections and microwave ablations.

\section{Discussion}

This study showed that CT-guided percutaneous HDR brachyablation yields high long-term tumor LC with low rates of procedural and treatment-related toxicities with a median follow-up time of 19 months. With $78.4 \%$ of tumors being ultra-centrally or centrally located, the 2- year LC was $96.2 \%$. Only 4 patients developed transient acute toxicities, all of which were grade $1-2$, and no patients developed late toxicities. However, about half of patients developed disease progression outside the irradiated area and2-year PFS was 29.7\%, underscoring a multi-disciplinary approach whenever managing patients with any degree of metastatic disease.

Brachyablation for lung tumors was first introduced outside the United States with a focus on low-dose rate (LDR) approaches. A meta-analysis of 296 patients from 5 clinical trials with advanced lung cancer patients 
reported the addition of LDR iodine-125 brachytherapy to chemotherapy was associated with improved tumor response $(\mathrm{RR}=1.85,95 \% \mathrm{CI} 1.54-2.22, P<0.001)$ and disease control $(R R=1.19,95 \%$ CI $1.10-1.29, P<0.001)$; these gains were not associated with improvement in OS [15]. Although LDR is associated with greater sparing of normal late-responding tissues such as the lung, it has also been associated with less tumor cell killing [16].

Interest in HDR brachyablation in the management of pulmonary tumors has recently grown; yet, to our knowledge this is the first report from an institution in the United States. The findings in our analyses support related experiences outside the United States that similarly reported high rates of long-term $\mathrm{LC}$ with a favorable safety profile in patients with central lung tumors. These include data from a phase I study in Germany reported by Ricke et al. in 2004 that demonstrated 97\% LC in 15 patients with 30 lung tumors treated to at least $20 \mathrm{~Gy}$ in a single fraction with $5+$ months of median follow-up [17]. Peters et al. in 2008 demonstrated 1-year LC of $91 \%$ after treating 30 patients with 83 primary and secondary lung malignancies to at least 20 Gy in a single fraction in a single-arm phase 2 study [18].

The experience of a third group in Germany, reported by Tselis et al. in 2011, was reported in a retrospective analysis on 55 patients with 60 tumors who received a median dose of 20 Gy (range 7-32) with multi-fractionated treatments; approximately half of their patients received twice-daily fractions of median 6 Gy per fraction, whereas the other half received once daily fractions with a median of 8 Gy per fraction [19]. After a median follow-up of 14 months, 2-year LC rates were $82 \%$ for metastatic tumors, and $79 \%$ for primary and locally recurrent intrathoracic lesions. Although high, the LC rates from this retrospective study were relatively lower than those from our study. Differences in control may be due to dose fractionation as clinical evidence suggests that tumor cell killing with single fraction HDR radiation may be more effective for late-responding tissues compared to a multi-fractionated regimen [16, 20]. Furthermore, early studies from SBRT for NSCLC showed delivering $\mathrm{BED}_{3}>100$ Gy to tumor was significantly correlated with improved $\mathrm{LC}$, which some patients in this study may not have received and led to the relatively lower LC rates compared to our study [21, 22].

By nature of its "inside-out" radiation delivery, brachyablation maximizes the therapeutic ratio by delivering tumoricidal doses with a sharp dose drop-off outside the tumor; therefore, potentially improving upon the dose distribution compared to SBRT [23]. Although early studies from small $(<5 \mathrm{~cm}$ in diameter) peripheral earlystage NSCLC and metastatic lung tumors demonstrated 5-year LC of $92-93 \%$ [22, 24], SBRT can potentially cause severe toxicities when treating centrally located tumors. In a landmark phase 2 trial, 2 -year freedom from severe (grade $3-5$ ) toxicity of only $54 \%$ for patients with central tumors compared to $83 \%$ for those with peripherally located tumors after receiving 60-66 Gy in 3 fractions [6]. More acceptable toxicity rates were achieved by delivering the total radiation dose over a greater number of treatment fractions [25]. The risk for developing severe or fatal toxicities still poses a challenge when treating ultra-central tumors with SBRT [4, 5, 26, 27]. It is notable that while the majority of patients in our study had (ultra) central lesions, favorable LC rates were achieved with minimal morbidity after just a single fraction of high dose radiation.Moreover, doses to the normal ipsilateral lung and critical mediastinal structures were low.

HDR brachyablation has an advantage over SBRT due to the relatively smaller volume of tissue radiated. Respiratory motion introduces uncertainty to tumor localization during SBRT treatment planning. Despite various strategies to manage respiratory motion, a margin of normal lung tissue surrounding the target is added during SBRT to account for this uncertainty. In contrast, brachytherapy catheters are directly implanted into the tumor and eliminate uncertainties from respiration [28, 29]. Additionally, due to the increasing utilization of immunotherapy there is interest in reducing volume of normal tissues receiving low doses, in order to minimize immunosuppressive effects. Future comparative dosimetric analyses between HDR brachyablation and SBRT are of high interest.

Incidence of procedural complications in our study was higher compared to previous experiences with HDR brachyablation but comparable to reports with IGTA [17-19, 30-33]. In our study, minor pneumothorax was associated with $33.3 \%$ of procedures (representing $44 \%$ of patients) and major pneumothorax in $10.3 \%$ of procedures (12\% of patients). Prior HDR brachyablation studies reported approximately $12 \%$ of patients developing minor pneumothorax and one patient developing a major pneumothorax $[18,19]$. Discrepancies in procedural complication rates may be attributed to operator expertise and/or our brachytherapy catheter implantation techniques. Also, all patients in our cohort underwent routine post-procedure surveillance CT scans whereas potentially in other series only chest $\mathrm{x}$-ray was utilized. Detection of small pneumothoraces is much higher with $\mathrm{CT}$ as compared to chest X-ray [34, 35]. Tumor access 
was achieved using a 17-gauge co-axial needle through which a $4 \mathrm{~F}$ catheter was placed. The needle provided continuous structural support for the catheter to prevent unwanted migration from its initial placement. In comparison, prior brachytherapy studies placed an 18-gauge introducer needle followed by guidewire exchange for $6 \mathrm{~F}$ angiography sheath and 16-gauge catheter, or placement of traditional 6F brachytherapy plastic catheter with rigid inner obturator. Utilizing a smaller needle gauge allowed better access to smaller and central tumors, including hilar and mediastinal targets. The resultant range of treated tumor volumes was generally smaller compared to related studies [17-19].

The overall lower peri-procedural complications reported in previous HDR brachyablation studies compared to IGTA may be due to differences in biologic effects. Cytotoxic effects from radiation occur over weeks to months whereas IGTA causes instantaneous cell death and necrosis. The less immediate structural changes with radiation may slow tissue reorganization and mitigate the formation of pneumothoraces [16, 30]. Injection of hydrogel biosealant upon needle removal has also shown to decrease chest tube insertion rates during lung biopsy, although pneumothorax rates have varied between studies $[36,37]$.

Interstitial HDR brachyablation may also overcome some limitations faced with IGTA. IGTA is better suited for peripheral, small tumors, and generally avoided for central tumors near mediastinal or large bronchial structures, diaphragm, or larger blood vessels HDR brachyablation can safely and effectively treat central and ultra-central tumors that were not possible or potentially ineffective with IGTA. Not only can brachyablation better protect neighboring organs with its sharp dose gradient, but 3D computer-generated radiation TPS calculates an optimal dose distribution prior to treatment delivery and can minimize the delivery of excessively high doses to critical nearby structures. Precise dose measurements cannot be calculated with IGTA since several factors impacting energy deposition; including thermal conductivity, impedance, and perfusion; cannot be accounted at the time of the procedure.

An intriguing finding in this report is that LC following HDR brachyablation was not shown to depend on tumor size as it does with IGTA $[18,19]$. This may be related to the use of a TPS that ensures adequate coverage of each tumor to its surface. This series demonstrated high rates of LC at 2 years for tumors with an average volume of $11.6 \mathrm{~cm}^{3}$ (range $0.57-62.8$ ), while LC declines when treating tumor volumes greater than $3 \mathrm{~cm}$ in diameter with IGTA $[9,31,38,39]$. from the use of multiple catheters to attain optimal dosimetry to ensure adequate tumor coverage and deliver non-uniform doses that can facilitate the delivery of very high doses to certain regions of the tumor while minimizing exposure to critical structures that may juxtapose on another edge of the target. This provides the option to intentionally deliver treatment in a non-homogenous manner which can boost intratumoral areas that may exhibit more radioresistant properties that may be identified by hypoxic radiographic signatures $[20,40]$.

This study has several limitations that deserve mention as the findings may not be widely generalizable. This study cohort was highly selected and represented a small and heterogeneous cohort. The outcomes of procedural studies often rely on technical and institutional expertise, thus complication rates may be higher in less experienced centers. The use of CTCAE criteria has been associated with under-reporting acute and late toxicities by physicians [41, 42]. Likewise, assessment of tumor response is subject to bias especially when radiation-related changes or other pathologies are present. In this study, tumor response was independently reviewed by two radiation oncologists and a thoracic radiologist using a prospectively validated criteria to mitigate this risk, and there was high agreement between physicians. As familiarity and experience with brachytherapy grows, further studies with larger cohort of central lung tumors are warranted. Furthermore, managing pulmonary tumors with HDR brachyablation should be made in a multi-disciplinary setting and performed in a high-volume brachytherapy facility. Engagement with Interventional Radiology physicians is highly recommended.

\section{Conclusion}

This study demonstrates that percutaneous HDR brachyablation is a promising therapeutic option to eradicate centrally and ultra-centrally located primary and metastatic lung tumors. Larger studies are needed to confirm its safety and efficacy as well as future comparisons to stereotactic body radiotherapy and other ablative techniques are warranted to expand multi-disciplinary management options. 


\begin{abstract}
Abbreviations
AAPM: The American Association for Physicists in Medicine; BED: Biologic effective dose; CT: Computed tomography; CTCAE: Common terminology criteria for adverse events; CTV: Clinical target volume; EQD2: Equivalent dose in 2 Gy per fraction; HDR: High-dose rate; IGTA: Image-guided thermal ablation; LC: Local control; LDR: Low-dose rate; MWA: Microwave ablation; NSCLC: Nonsmall cell lung cancer; OAR: Organ-at-risk; OS: Overall survival; PFS: Progression free survival; RECIST: Response evaluation criteria for solid tumors; RFA: Radiofrequency ablation; RR: Relative risk; SBRT: Stereotactic body radiotherapy; SD: Standard deviation; TPS: Treatment planning system.Supplementary information

The online version contains supplementary material available at https://doi. org/10.1186/s13014-021-01826-1.
\end{abstract}

Additional file 1. Derivation of biologic effective dose and equivalent dose in $2 \mathrm{~Gy}$ per fraction.

\section{Acknowledgements}

Not applicable.

\section{Authors' contributions}

All authors have made substantial contributions to the conception/design of the work; SY and AJC acquired and the data; SY, RS, and AJC interpreted data; $S Y, R S, A F, M K, A J C$ have drafted or substantively reviewed the work; all authors have approved the submitted version and agree to be personally accountable for author's own contributions. All authors read and approved the final manuscript.

\section{Funding}

This research did not receive any specific grant from funding agencies in the public, commercial or non-profit sectors.

\section{Availability of data and materials}

The datasets used and/or analyzed during the current study are available from the corresponding author on reasonable request.

\section{Data access and integrity}

The authors declare that they had full access to all the data in this study and the authors take complete responsibility for the integrity of the data and the accuracy of the data analysis.

\section{Declarations}

\section{Ethics approval and consent to participate}

This investigation performed in accordance with the Declaration of Helsinki and was approved by the Institutional Review Board.

\section{Consent for publication}

Not applicable.

\section{Competing interests}

The authors declare that they have no competing interest.

\section{Author details}

${ }^{1}$ Department of Radiation Oncology, University of California Los Angeles, 200 Medical Plaza Driveway, Suite B265, Los Angeles, CA 90095, USA. ²Department of Radiology Thoracic Interventional Services, University of California Los Angeles, Los Angeles, CA 90095, USA. ${ }^{3}$ Department of Radiation Oncology, Veterans Affairs Greater Los Angeles, Los Angeles, CA 90073, USA. ${ }^{\text {DDepart- }}$ ment of Radiation Oncology, Cedars-Sinai Medical Center, Los Angeles, CA 90048, USA. ${ }^{5}$ Department of Hematology and Medical Oncology, University of California Los Angeles, Los Angeles, CA 90095, USA.

Received: 11 February 2021 Accepted: 28 May 2021

Published online: 07 June 2021

\section{References}

1. Bi N, Shedden K, Zheng X, Kong F. Comparison of the effectiveness of radiofrequency ablation with stereotactic body radiation therapy in inoperable stage i non-small cell lung cancer: a systemic review and meta-analysis. Pract Radiat Oncol. 2013;3(2 Suppl 1):S19.

2. Raman S, Yau V, Pineda S, Le LW, Lau A, Bezjak A, et al. Ultracentral tumors treated with stereotactic body radiotherapy: single-institution experience. Clin Lung Cancer. 2018;19(5):e803-10.

3. Horne ZD, Richman AH, Dohopolski MJ, Clump DA, Burton SA, Heron DE. Stereotactic body radiation therapy for isolated hilar and mediastinal non-small cell lung cancers. Lung Cancer. 2018;115:1-4.

4. Tekatli H, Haasbeek N, Dahele M, De Haan P, Verbakel W, Bongers E, et al. Outcomes of hypofractionated high-dose radiotherapy in poor-risk patients with "ultracentral" non-small cell lung cancer. J Thoracic Oncol. 2016;11(7):1081-9.

5. Wang C, Sidiqi BU, Yorke ED, McKnight D, Dick-Godfrey R, Torres D, et al. Toxicity and local control in "ultra-central" lung tumors treated with stereotactic body radiation therapy (SBRT). Int J Radiat Oncol Biol Phys. 2018;102(3):S10.

6. Timmerman R, McGarry R, Yiannoutsos C, Papiez L, Tudor K, DeLuca J, et al. Excessive toxicity when treating central tumors in a phase II study of stereotactic body radiation therapy for medically inoperable early-stage lung cancer. J Clin Oncol. 2006;24(30):4833-9.

7. Hiraki T, Gobara H, Fujiwara H, Ishii H, Tomita K, Uka M, et al. Lung cancer ablation: complications. Semin Interv Radiol. 2013;30(2):169-75.

8. Kashima M, Yamakado K, Takaki H, Kodama H, Yamada T, Uraki J, et al. Complications after 1000 lung radiofrequency ablation sessions in 420 patients: a single center's experiences. AJR Am J Roentgenol. 2011;197(4):W576-80

9. Dupuy DE, Fernando HC, Hillman S, Ng T, Tan AD, Sharma A, et al. Radiofrequency ablation of stage IA non-small cell lung cancer in medically inoperable patients: results from the American College of Surgeons Oncology Group Z4033 (Alliance) trial. Cancer. 2015;121(19):3491-8.

10. Palma DA, Olson R, Harrow S, Gaede S, Louie AV, Haasbeek C, et al. Stereotactic ablative radiotherapy versus standard of care palliative treatment in patients with oligometastatic cancers (SABR-COMET): a randomised, phase 2, open-label trial. Lancet. 2019;393(10185):2051-8.

11. Cushman TR, Gomez D, Kumar R, Likacheva A, Chang JY, Cadena AP, et al. Combining radiation plus immunotherapy to improve systemic immune response. JThorac Dis. 2018;10(Suppl 3):S468-79.

12. Network NCC. NCCN clinical practice guidelines in oncology: non-small cell lung cancer (Version 8.2020). Available from: https://www.ncen.org/ professionals/physician_gls/pdf/nscl.pdf.

13. Benedict SH, Yenice KM, Followill D, Galvin JM, Hinson W, Kavanagh B, et al. Stereotactic body radiation therapy: the report of AAPM Task Group 101. Med Phys. 2010;37(8):4078-101.

14. Schwartz LH, Litière S, de Vries E, Ford R, Gwyther S, Mandrekar S, et al. RECIST 11-update and clarification: from the RECIST committee. Eur J Cancer. 2016;62:132-7.

15. Qiu H, Ji J, Shao Z, Wang J, Ma G, Zhang L, et al. the efficacy and safety of iodine-125 brachytherapy combined with chemotherapy in treatment of advanced lung cancer: a meta-analysis. J College Phys Surg Pakistan. 2017:27(4):237-45.

16. Manning MA, Zwicker RD, Arthur DW, Arnfield M. Biologic treatment planning for high-dose-rate brachytherapy. Int J Radiat Oncol Biol Phys. 2001;49(3):839-45.

17. Ricke J, Wust P, Wieners G, Hengst S, Pech M, Lopez Hänninen E, et al. CTguided interstitial single-fraction brachytherapy of lung tumors: phase I results of a novel technique. Chest. 2005;127(6):2237-42.

18. Peters N, Wieners G, Pech M, Hengst S, Rühl R, Streitparth F, et al. CT-guided interstitial brachytherapy of primary and secondary lung malignancies: results of a prospective phase II trial. Strahlentherapie und Onkologie Organ der Deutschen Rontgengesellschaft [et al]. 2008;184(6):296-301.

19. Tselis N, Ferentinos K, Kolotas C, Schirren J, Baltas D, Antonakakis A, et al. Computed tomography-guided interstitial high-dose-rate brachytherapy in the local treatment of primary and secondary intrathoracic malignancies. J Thorac Oncol. 2011;6(3):545-52.

20. Hall EJGA. Radiobiology for the radiologist. 8th ed. Philadelphia: Wolters Kluwer; 2019 
21. Willner J, Baier K, Caragiani E, Tschammler A, Flentje M. Dose, volume, and tumor control prediction in primary radiotherapy of non-small-cell lung cancer. Int J Radiat Oncol Biol Phys. 2002;52(2):382-9.

22. Onishi H, Shirato H, Nagata Y, Hiraoka M, Fujino M, Gomi K, et al. Hypofractionated stereotactic radiotherapy (HypoFXSRT) for stage I non-small cell lung cancer: updated results of 257 patients in a Japanese multiinstitutional study. J Thoracic Oncol. 2007:2(7 Suppl 3):S94-100.

23. Hass P, Mohnike K, Kropf S, Brunner TB, Walke M, Albers D, et al. Comparative analysis between interstitial brachytherapy and stereotactic body irradiation for local ablation in liver malignancies. Brachytherapy. 2019;18(6):823-8.

24. Timmerman R, Paulus R, Galvin J, Michalski J, Straube W, Bradley J, et al. Stereotactic body radiation therapy for inoperable early stage lung cancer. JAMA. 2010;303(11):1070-6.

25. Senthi S, Haasbeek CJ, Slotman BJ, Senan S. Outcomes of stereotactic ablative radiotherapy for central lung tumours: a systematic review. Radiother Oncol. 2013;106(3):276-82.

26. Lindberg K, Bergström P, Brustugun OT, Engelholm S, Grozman V, Hoyer $M$, et al. OA2405 the nordic HILUS-trial - first report of a phase II trial of SBRT of centrally located lung tumors. J Thoracic Oncol. 2017;12(1):S340.

27. Lindberg K, Grozman V, Karlsson K, Lindberg S, Lax I, Wersäll P, et al. The HILUS-trial; a prospective Nordic multi-center phase II study of ultra-central lung tumors treated with stereotactic body radiotherapy. J Thoracic Oncol.

28. Whyte RI, Crownover R, Murphy MJ, Martin DP, Rice TW, DeCamp MM Jr, et al. Stereotactic radiosurgery for lung tumors: preliminary report of a phase I trial. Ann Thorac Surg. 2003;75(4):1097-101.

29. Negoro Y, Nagata Y, Aoki T, Mizowaki T, Araki N, Takayama K, et al. The effectiveness of an immobilization device in conformal radiotherapy for lung tumor: reduction of respiratory tumor movement and evaluation of the daily setup accuracy. Int J Radiat Oncol Biol Phys. 2001:50(4):889-98.

30. Sharma DN, Rath GK, Thulkar S, Bahl A, Pandit S, Julka PK. Computerized tomography-guided percutaneous high-dose-rate interstitial brachytherapy for malignant lung lesions. J Cancer Res Ther. 2011;7(2):174-9.

31. de Baère T, Aupérin A, Deschamps F, Chevallier P, Gaubert Y, Boige $V$, et al. Radiofrequency ablation is a valid treatment option for lung metastases: experience in 566 patients with 1037 metastases. Ann Oncol. 2015;26(5):987-91.

32. Okuma T, Matsuoka T, Yamamoto A, Oyama Y, Toyoshima M, Nakamura K, et al. Frequency and risk factors of various complications after computed tomography-guided radiofrequency ablation of lung tumors. Cardiovasc Intervent Radiol. 2008;31(1):122-30.

33. Welch BT, Brinjikji W, Schmit GD, Callstrom MR, Kurup AN, Cloft HJ, et al. A national analysis of the complications, cost, and mortality of percutaneous lung ablation. J Vasc Intervent Radiol. 2015;26(6):787-91.

34. Traub M, Stevenson M, McEvoy S, Briggs G, Lo SK, Leibman S, et al. The use of chest computed tomography versus chest $X$-ray in patients with major blunt trauma. Injury. 2007;38(1):43-7.

35. Omar HR, Mangar D, Khetarpal S, Shapiro DH, Kolla J, Rashad R, et al. Anteroposterior chest radiograph vs chest CT scan in early detection of pneumothorax in trauma patients. Int Arch Med. 2011;4(1):30.

36. Zaetta JM, Licht MO, Fisher JS, Avelar RL, Bio-Seal Study G. A lung biopsy tract plug for reduction of postbiopsy pneumothorax and other complications: results of a prospective, multicenter, randomized, controlled clinical study. J Vasc Intervent Radiol. 2010;21(8):1235-43.e1-3.

37. Ahrar JU, Gupta S, Ensor JE, Mahvash A, Sabir SH, Steele JR, et al. Efficacy of a self-expanding tract sealant device in the reduction of pneumothorax and chest tube placement rates after percutaneous lung biopsy: a matched controlled study using propensity score analysis. Cardiovasc Intervent Radiol. 2017:40(2):270-6.

38. Zhu JC, Yan TD, Morris DL. A systematic review of radiofrequency ablation for lung tumors. Ann Surg Oncol. 2008;15(6):1765-74.

39. Callstrom MR, Woodrum DA, Nichols FC, Palussiere J, Buy X, Suh RD, et al. Multicenter study of metastatic lung tumors targeted by interventional cryoablation evaluation (SOLSTICE). J Thoracic Oncol. 2020;15(7):1200-9.

40. Ruggieri R, Naccarato S, Nahum AE. Severe hypofractionation: nonhomogeneous tumour dose delivery can counteract tumour hypoxia. Acta Oncologica (Stockholm, Sweden). 2010;49(8):1304-14.

41. Flores LT, Bennett AV, Law EB, Hajj C, Griffith MP, Goodman KA. Patientreported outcomes vs clinician symptom reporting during chemoradiation for rectal cancer. Gastrointest Cancer Res. 2012:5(4):119-24.

42. Di Maio M, Gallo C, Leighl NB, Piccirillo MC, Daniele G, Nuzzo F, et al. Symptomatic toxicities experienced during anticancer treatment: agreement between patient and physician reporting in three randomized trials. J Clin Oncol. 2015;33(8):910-5.

\section{Publisher's Note}

Springer Nature remains neutral with regard to jurisdictional claims in published maps and institutional affiliations.
Ready to submit your research? Choose BMC and benefit from:

- fast, convenient online submission

- thorough peer review by experienced researchers in your field

- rapid publication on acceptance

- support for research data, including large and complex data types

- gold Open Access which fosters wider collaboration and increased citations

- maximum visibility for your research: over $100 \mathrm{M}$ website views per year

At BMC, research is always in progress.

Learn more biomedcentral.com/submissions 